\title{
Is er een trade-off tussen wetenschappelijke impact en praktijkrelevantie?
}

\author{
Een analyse van de publicaties van bestuurs- en politieke \\ wetenschappers in Nederland (2006-2011)
}

Sandra Groeneveld, Robin Bouwman \& Steven Van de Walle

In dit artikel onderzoeken we of de veronderstelde tweedeling tussen internationaal publiceren met een sterke focus op impactfactoren en praktijkgericht publiceren ook daadwerkelijk zichtbaar is in de manier waarop individuele Nederlandse bestuurs- en politieke wetenschappers publiceren. Het artikel biedt daarmee nieuw empirisch bewijs ter onderbouwing van de discussie over welke route de bestuurs- en politieke wetenschappen zouden moeten kiezen. Drie publicatieprofielen komen uit de analyse naar voren: een professioneel profiel met een relatief hoog aandeel professionele publicaties, een internationaal profiel met een relatief hoog aandeel publicaties in internationale wetenschappelijke tijdschriften, en een traditioneel profiel met een bescheidener aantal publicaties gelijkelijk verdeeld over nationale en internationale professionele en wetenschappelijke publicaties. De onderscheiden profielen tonen dat er van een trade-off tussen praktijkgericht en internationaal wetenschappelijk publiceren sprake is, maar dat enkel tot op zekere hoogte. Ook zien we dat het publicatieprofiel samenhangt met de plaats waar men is gepromoveerd (buitenland of niet), en de universiteit waar men werkt.

\section{Inleiding}

De relatie tussen bestuurskunde en bestuurspraktijk roept veel emoties op. De bestuurskunde wordt vaak omschreven als een praktijkgerichte discipline (Frissen \& Van Twist, 2010), maar tegelijk zien we dat een sterke 'academisering' gaande is. Enerzijds kan de bestuurskunde worden gezien als een discipline die zich dienend dient op te stellen richting het openbaar bestuur. Dit betekent dat er grote aandacht dient te zijn voor het opleiden van toekomstige generaties ambtenaren en bestuurders, en dat onderzoek zich in de eerste plaats dient te richten op problemen waarmee het (nationale) openbare bestuur te kampen heeft. Publicaties hebben daarom ook de ambtenaar en de student als beoogd publiek. Anderzijds kan de bestuurskunde ook worden beschouwd als een zuiver academische discipline, die het openbaar bestuur enkel als onderzoeksobject beschouwt en geen

* Het onderzoek dat tot deze resultaten heeft geleid, is deels gefinancierd door het Zevende Kaderprogramma van de Europese Unie, onder overeenkomst nr. 266887 (Project COCOPS), Socio-economic Sciences and Humanities. 
nationale of morele binding heeft met het openbaar bestuur. De publicatie van onderzoeksresultaten moet zich dan in de eerste plaats richten op internationale academische tijdschriften.

Hoewel iets verder verwijderd van de dagelijkse praktijk van bestuur, is de discussie binnen de politieke wetenschap vergelijkbaar. Het verwijt gaat dat politicologen zich steeds verder bekwamen in methodologie ten koste van inzichten in de dagelijkse politieke praktijk en het laten horen van een stem in het maatschappelijke debat (zie bijvoorbeeld Eisfeld, 2011; Trent, 2011). De beslissing van de Amerikaanse Senaat om de National Science Foundation (NSF) te verbieden nog langer politieke wetenschap te financieren is deels gerelateerd aan het dubbele verwijt dat de discipline niet 'wetenschappelijk' én niet maatschappelijk relevant zou zijn (Mole, 2013).

Het recente NWO-MaGW-onderzoek naar publicatieculturen (2013) toont dat de bestuurskunde en de politicologie niet enkel gericht zijn op het publiceren van artikelen in refereed tijdschriften, maar ook andere publicatiecategorieën waarderen. Beide disciplines hebben geen duidelijk afgebakende lijst toptijdschriften, en hebben een respectievelijk sterk en gematigd gevarieerde publicatiecultuur. Binnen de bestuurskunde ligt de focus iets minder sterk op internationaal publiceren dan het geval is voor de politicologie. Het NWO-MaGW-onderzoek (2013, p. 42) spreekt daarnaast over het bestaan van twee stromingen in publicatiecultuur in de bestuurskunde - één gericht op nationale publicaties en banden met het werkveld, de andere op internationale publicaties. In de politicologie constateert het onderzoek een veel verder doorgedreven internationalisering van de publicatiecultuur, en een iets grotere homogeniteit (NWO-MaGW, 2013, pp. 43-44).

In de academische wereld zien we echter een steeds sterker wordende trend tot internationalisering, en worden beoordelingssystemen ingevoerd die academisch publiceren stimuleren. Dit heeft zowel binnen de academische discipline als in de bestuurs- en politieke praktijk geleid tot discussies over de gevolgen van wetenschappelijk publiceren in internationale tijdschriften voor de praktijkrelevantie (zie bijvoorbeeld de discussies op de NIG-conferenties in 2010 en 2014 en het Festival der Bestuurskunde in 2010, conform Van Bueren, 2010). Een veelgehoorde klacht is dat de nadruk op internationaal publiceren heeft geleid tot een situatie waarin veel onderzoekers niet langer de tijd of de incentives hebben om hun werk te verspreiden via (nationale) praktijkrelevante publicaties of professionele outlets. Dit betekent dat niet-Engelstalige media onder druk komen te staan, en dat onderzoek met een hoofdzakelijk nationale focus minder makkelijk zijn weg vindt naar tijdschriften. Het gaat dus met andere woorden niet enkel om een taalissue, maar ook om een inhoudelijke verschuiving (zie Van Bueren, 2010).

In dit artikel onderzoeken we of de tweedeling in de discipline tussen internationaal publiceren met een sterke focus op impactfactoren en praktijkgericht publiceren ook daadwerkelijk zichtbaar is in de manier waarop individuele Nederlandse bestuurs- en politieke wetenschappers publiceren. Meer specifiek wordt gekeken 
of er voor individuele wetenschappers een trade-off bestaat tussen internationaal academisch publiceren en publiceren voor de nationale markt en de bestuurs- en politieke praktijk, en worden publicatiepatronen gekoppeld aan de kenmerken van de onderzoekers. De volgende vragen staan centraal:

- Welke publicatiepatronen zijn er waar te nemen onder bestuurs- en politieke wetenschappers in Nederland?

- Is er voor individuele wetenschappers een trade-off tussen internationaal publiceren en nationale en professionele publicaties?

- Wat zijn de kenmerken van de academici die behoren tot een bepaald publicatiecluster?

Met de beantwoording van deze vragen beogen we de assumptie dat er sprake is van een trade-off te toetsen om vervolgens de discussie over welke route de bestuurs- en politieke wetenschappen zouden moeten kiezen, beter gefundeerd te kunnen voeren. Hierna staan we eerst kort stil bij de belangrijkste dilemma's die in debatten over wetenschappelijk publiceren in de bestuurs- en politieke wetenschappen naar voren komen. Vervolgens presenteren we onze analyses van de publicaties van bestuurs- en politieke wetenschappers in Nederland.

\section{Bestuurskunde tussen bestuurswetenschap en bestuurspraktijk}

Tussen bestuurskundige theorie en bestuurspraktijk bestaat een innige band (Waldo, 1955). De discipline wordt meestal beschouwd als een professionele discipline, net als bijvoorbeeld geneeskunde, recht of architectuur. Tegelijk zijn de praktijklessen die uit de bestuurskunde kunnen worden afgeleid niet altijd duidelijk, en zijn ze niet altijd richtinggevend voor de praktijk. Een sterke band tussen theorie en praktijk wordt als noodzakelijk gezien, maar verdere samenwerking tussen onderzoekers en managers stuit ook op de nodige scepsis (Kieser \& Leiner, 2012). Ook het basisprincipe dat onderzoek direct bruikbaar moet zijn voor bestuurders, wordt niet algemeen ondersteund. Overigens zien we dezelfde discussie ook in het bredere managementonderzoek: dient managementonderzoek bruikbaar te zijn voor managers, en kan dit (Kieser \& Leiner, 2009)? Deze kloof uit zich ook in de keuze voor de thema's die worden onderzocht, waarbij academici en praktijk andere voorkeuren hebben (zie Gibson \& Deadrick, 2010; Streib, Slotkin, \& Rivera, 2001).

De kloof tussen bestuurswetenschap en bestuurspraktijk is een terugkerend thema, niet enkel in de Nederlandse bestuurskunde (zie bijvoorbeeld Gibson \& Deadrick, 2010). De kloof tussen beide wordt meer en meer als vrij groot ervaren, zeker in vergelijking tot de vroege generaties bestuurskundigen die als 'pracademics' door het leven gingen (Bushouse, Jacobson, Lambright, Llorens, Morse, \& Poocharoen, 2011). In onderzoek bij de topacademici in het vakgebied kwam een duidelijke tweedeling naar voren: zij die expliciet de brug proberen te maken met de praktijk, en zij die zich in de eerste plaats richten op academische bladen (Schroeder, O’Leary, Jones, \& Poocharoen, 2004). 
Bestuurskunde als academische discipline wordt er tegelijk van beschuldigd onvoldoende toepassingsgericht te zijn, een gebrek te hebben aan eigen theorieën, en methodologisch onderontwikkeld te zijn. De roep om een meer 'wetenschappelijke' bestuurskunde is dan ook niet nieuw. Toch zien we ook pogingen om de praktijk terug binnen te brengen in het academische. Een goed voorbeeld hiervan is het leidende blad Public Administration Review, dat opnieuw meer plaats heeft ingeruimd voor de praktijk. Een andere aanduiding zien we in de International Review of Administrative Sciences, die sinds enkele jaren niet alleen een samenvatting van het artikel vereist, maar auteurs ook expliciet vraagt naar 'points for practitioners'. Toch zien we dat de traditie waarin mensen uit de praktijk publiceerden in wetenschappelijke bladen grotendeels is verdwenen. Het aandeel practitioners in de bestuurskundige bladen is erg laag (Kellough \& Pitts, 2005).

\section{Politicologie tussen wetenschap en maatschappij}

Een soortgelijk debat woedt over de politicologie en haar plaats in de maatschappij (zie bijvoorbeeld Flinders \& John, 2013). Dit debat wordt gevoed door de zorg dat de politicologie haar plaats in het publieke debat heeft opgegeven (Putnam, 2003). Redenen voor deze verschuiving worden gezocht in de richting van de professionalisering van de discipline en een steeds sterker wordende specialisatie van onderzoekers (Trent, 2011). Meer bepaald leeft de vraag of politicologen wel de juiste onderzoeksthema's kiezen, en of professionalisering van de discipline en de bijhorende aandacht voor formal modelling en zelfs een zekere mate van physics envy er niet toe heeft geleid dat de politicologie steeds minder relevant is geworden. Ook de prestatienormen die worden gehanteerd binnen de discipline, kunnen bijdragen aan een heroriëntatie van de professionele doelstellingen. Binnen de politicologie is duidelijk een tegenbeweging zichtbaar, denk maar aan de Perestroika-beweging, die ijvert voor een toegankelijker politicologie die relevanter is voor leken (zie voor een overzicht Renwick Monroe, 2005).

Prescriptie lijkt al vroeg uit de leidende tijdschriften te zijn verdwenen (Stoker, 2010). De vraag of politicologen wel horen deel te nemen aan publieke debatten duikt herhaaldelijk op, en tegelijk wordt gediscussieerd over de vraag of de politicologie wel in staat is of in staat hoort te zijn om oplossingen te bieden voor alledaagse politieke problemen.

\section{Data en methode}

Op basis van een clusteranalyse op de publicatie-output van leden van de landelijke onderzoeksschool Netherlands Institute of Government (NIG) wordt inzicht gegeven in de publicatiepatronen in de bestuurswetenschappen en die van een deel van de politieke wetenschappen in Nederland. De meeste bestuurswetenschappers en een aanzienlijk deel van de politicologen in Nederland zijn aangesloten bij NIG. Lidmaatschap van NIG is verbonden aan een minimumaantal publicatiepunten in een periode van vijf jaar. Dit betekent dat de leden van NIG niet 
representatief zijn voor de populatie bestuurs- en politieke wetenschappers in Nederland. Wetenschappers die zeer weinig publiceren, vallen niet in onze onderzoeksgroep. Daarnaast zijn politicologen die werkzaam zijn aan een Nederlandse universiteit maar niet zijn aangesloten bij NIG niet in de onderzoeksgroep opgenomen (bijvoorbeeld de staf van de afdeling Politicologie van de UvA). Met name dit laatste kan vertekening opleveren in de publicatiepatronen die we zullen ontdekken. We komen hierop terug in de afsluitende paragraaf. De dataset bevat bovendien geen informatie over de disciplinaire achtergrond van de wetenschappers. We kunnen dan ook geen onderscheid maken tussen de publicatiepatronen van bestuurswetenschappers en politicologen. Ten slotte benadrukken we dat uitsluitend wetenschappers werkzaam aan Nederlandse universiteiten in de analyse zijn opgenomen; leden van NIG aan de Vlaamse universiteiten zijn buiten beschouwing gelaten.

We analyseren de publicatie-output van wetenschappers in de periode 20062011. Voor de analyse zijn publicatiegegevens gebruikt die samengebracht zijn in de wetenschappelijke jaarverslagen van NIG, die jaarlijks worden gepubliceerd via de website. Het totaal aantal personen in de dataset is 189 en betreft de gepromoveerde wetenschappelijke staf die in deze periode lid was of dat is geworden. Op basis van het totaal aantal publicaties in de periode 2006-2011 zijn uitschieters boven en onder drie standaardafwijkingen van het gemiddelde aantal publicaties weggelaten uit de analyse. Hiermee komt de onderzoeksgroep op 177 personen.

Volgens de NIG-systematiek worden publicaties ingedeeld in acht categorieën. Deze categorieën worden door ons gereduceerd tot vijf: internationale artikelen, nationale artikelen, internationale boeken en hoofdstukken, nationale boeken en hoofdstukken (telkens peer reviewed) en professionele publicaties. Deze laatste categorie bevat onder andere onderzoeksrapporten, bijdragen voor praktijkbladen, columns, en dergelijke meer, maar geen conferentiepapers of -presentaties. Professionele publicaties zijn hoofdzakelijk nationaal, maar kunnen ook internationaal zijn. Het editen van boeken wordt door NIG wel geclassificeerd, maar er wordt in de NIG-classificatie geen onderscheid gemaakt tussen nationale en internationale boeken. Aangezien het onderscheid tussen nationaal en internationaal publiceren in deze studie centraal staat, is daarom besloten book editorship buiten de analyse te laten. Daar komt bij dat afzonderlijke hoofdstukken in een 'edited volume' als aparte publicaties worden opgevoerd. Boekredacteuren verzorgen doorgaans ten minste een inleidend of afsluitend hoofdstuk in het desbetreffende boek. Deze hoofdstukken zijn wel in de analyse meegenomen.

Voor de clusteranalyse is gebruikgemaakt van SPSS versie 21. In een clusteranalyse worden cases, in dit geval wetenschappers, op basis van hun onderlinge verschillen en overeenkomsten ingedeeld in homogene groepen op basis van bepaalde kenmerken. In ons geval gaat het om kenmerken van hun publicaties, meer specifiek de gestandaardiseerde aantallen van iedere categorie publicatie. Er zijn verscheidene technieken om een clusteranalyse uit te voeren (Kaufman \& Rousseeuw, 2009; Rencher \& Christensen, 2002). Wij hebben gekozen voor de Two-Step-procedure, omdat in tegenstelling tot bijvoorbeeld K-means of hiërar- 
Tabel 1 Verdeling (in \%) van de typen publicaties per persoon per cluster in de periode 2006-2011 ( $N=177$ personen)

\begin{tabular}{llll}
\hline Cluster & I (N = 74 personen) & $\mathbf{2}$ (N = 65 personen) & $\mathbf{3}$ ( $\mathbf{N}=\mathbf{3 8}$ personen) \\
\hline $\begin{array}{l}\text { Internationale weten- } \\
\text { schappelijke artikelen }\end{array}$ & 15 & 36 & 17 \\
$\begin{array}{l}\text { Nationale wetenschap- } \\
\text { pelijke artikelen }\end{array}$ & 9 & 21 \\
$\begin{array}{l}\text { Professionele publica- } \\
\text { ties }\end{array}$ & 51 & 20 & 23 \\
$\begin{array}{l}\text { Internationale boek- } \\
\text { hoofdstukken en } \\
\text { monografieën }\end{array}$ & 16 & 31 & 18 \\
$\begin{array}{l}\text { Nationale boekhoofd- } \\
\text { stukken en monogra- } \\
\text { fieën }\end{array}$ & 8 & 4 & 21 \\
Totaal & 100 & 100 & 100 \\
\hline
\end{tabular}

chische methoden het Two-step-clusteralgoritme het aantal in de data aanwezige clusters identificeert en vervolgens cases aan de clusters toewijst. We hebben de Log-likelihood-methode toegepast. Om te voorkomen dat bijvoorbeeld de (relatief grote) hoeveelheid professionele publicaties een onevenredig grote invloed op de clusteranalyse zou hebben, worden de variabelen gestandaardiseerd. In een goede clusteroplossing lijken de cases in een cluster erg op elkaar, terwijl de clusters zelf niet op elkaar lijken. De silhouette coefficient is een maat voor de kwaliteit van de oplossing en kan een waarde tussen - 1 en 1 aannemen. Idealiter is de silhouette coefficient zo hoog mogelijk. In ons geval is de silhouette coefficient 0,4 , wat voldoende is (Norusis, 2011). Deze oplossing geeft drie clusters, die in de volgende paragraaf worden beschreven.

Naast de clustering van wetenschappers in de drie publicatieprofielen hebben we in de dataset enkele achtergrondkenmerken van de wetenschappers opgenomen. Dit zijn het geslacht (man $=1$ ), aantal jaren sinds promotie, en of men al dan niet in het buitenland gepromoveerd is (aan een Nederlandse universiteit $=1$ ).

\section{Resultaten}

Welke publicatiepatronen zijn er waar te nemen onder bestuurs- en politieke wetenschappers in Nederland?

De clusteranalyse geeft een clustering van de bij NIG aangesloten wetenschappers in drie clusters. Het eerste cluster bevat 74 personen (41,8\%), het tweede 65 personen $(36,7 \%)$ en het derde 38 personen $(21,5 \%)$. De clusteroplossing blijkt stabiel. In tabel 1 wordt per cluster weergegeven wat het gemiddelde aandeel van elk type publicatie in de totale publicatie-output in de onderzochte periode is. 
Figuur 1 Gemiddeld aantal publicaties per type publicatie, per cluster $(N=177)$

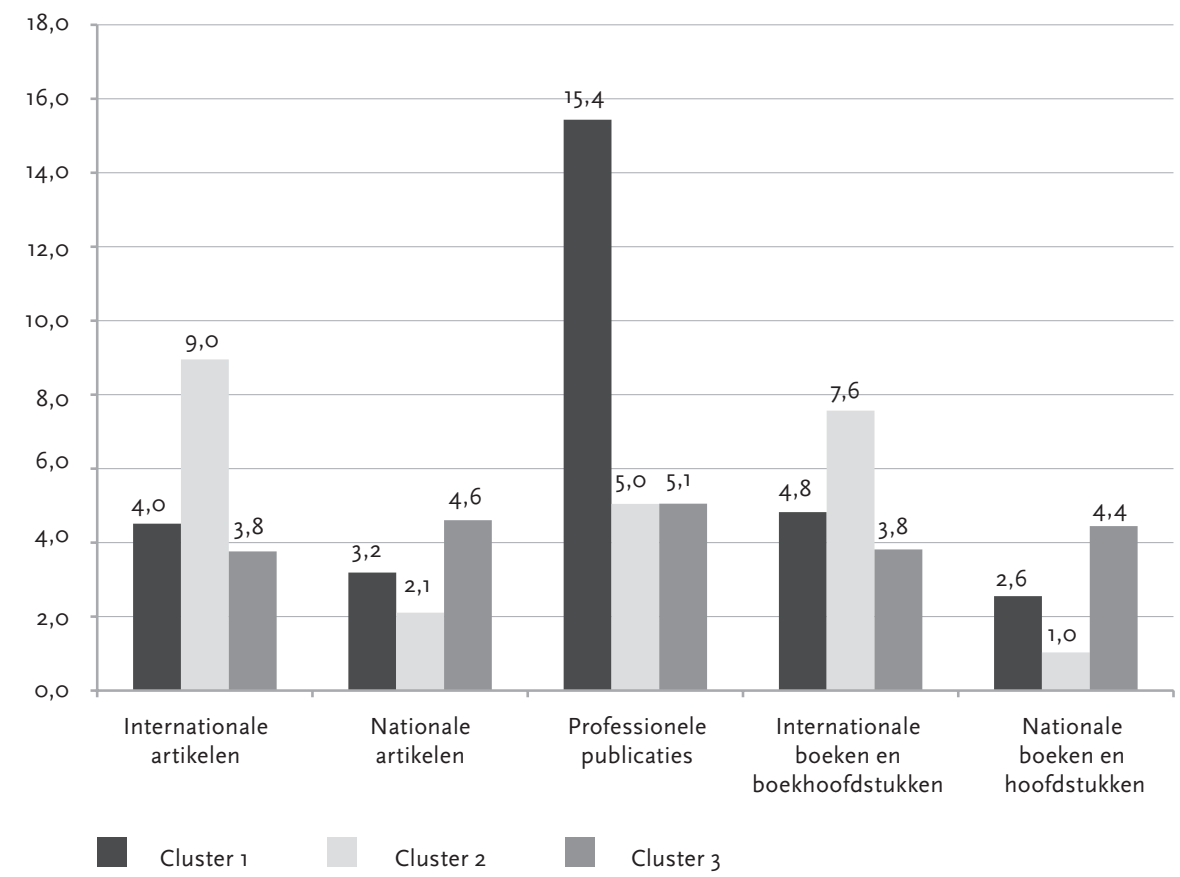

Voor wetenschappers in het eerste cluster is het aandeel professionele publicaties in hun totale output met $51 \%$ veruit het grootst en het aandeel nationale boekhoofdstukken en monografieën met $8 \%$ het laagst. Voor wetenschappers in het tweede cluster is het aandeel artikelen in internationale wetenschappelijke tijdschriften in hun totale output met $36 \%$ het grootst, op de voet gevolgd door het aandeel internationale boekhoofdstukken en monografieën. Het aandeel nationale boekhoofdstukken en monografieën is met $4 \%$ voor dit cluster het kleinst. Voor wetenschappers in het derde cluster is de output bijna evenredig over de verschillende typen publicaties verdeeld. Al met al zien we in cluster 2 een publicatieprofiel terug dat het meest overeenkomt met het internationale academische profiel, terwijl cluster 1 de meeste overeenkomsten vertoont met een meer nationaal en praktijkgericht profiel. Cluster 3 zit daar tussenin.

Is er voor individuele wetenschappers een trade-off tussen international publiceren en nationale en professionele publicaties?

$\mathrm{Nu}$ we aan de hand van de drie clusters de publicatiepatronen in de bestuurs- en politieke wetenschappen in Nederland hebben getypeerd, gaan we in op de vraag of een gerichtheid op internationaal publiceren ook betekent dat dit ten koste gaat van het aantal publicaties dat praktijkgericht is en gericht op een nationaal publiek. 
Daartoe beschrijven we per cluster het gemiddeld aantal publicaties per type. Figuur 1 vat de bevindingen samen. De publicatiepatronen die we naar aanleiding van tabel 1 beschreven, zijn ook hier duidelijk zichtbaar, met het internationale profiel van cluster 2 en het professionele profiel van cluster 1 . Bovendien blijkt uit de figuur dat wetenschappers met een internationaal profiel ook in absolute termen minder nationale en professionele publicaties hebben dan de wetenschappers in de andere twee clusters, terwijl wetenschappers met een professioneel profiel minder internationale publicaties hebben dan de wetenschappers in het internationale cluster, maar nog altijd iets meer dan de wetenschappers in het derde cluster. De wetenschappers in het derde cluster hebben bovendien gemiddeld meer nationale tijdschriftartikelen en nationale boeken en boekhoofdstukken en lijken daarmee ook een wat traditioneler academisch profiel te hebben. Hun publicatieprofiel combineert een nationale en internationale alsook een wetenschappelijke en praktijkgerichte oriëntatie, een combinatie die volgens de discussies over de ontwikkeling van de bestuurs- en politieke wetenschappen in het verleden veel gebruikelijker was.

Al met al lijkt er in enige mate van een trade-off sprake te zijn. Terwijl wetenschappers binnen de drie clusters verschillende typen publicaties hebben, leidt een professionele dan wel internationaal wetenschappelijke focus ertoe dat publicaties van een ander type minder talrijk zijn. Hieronder gaan we na of achtergrondkenmerken als academische leeftijd een rol spelen in de publicatieprofielen.

\section{Wat zijn de kenmerken van de academici die behoren tot een bepaald publicatiecluster?} Onder academische leeftijd verstaan we het aantal jaren dat verstreken is sinds het jaar van promotie. Op grond van de beschrijving van de clusters op basis van de gemiddelde aantallen publicaties per type verwachten we dat het derde cluster het meest traditioneel is, en daarom ook gemiddeld het 'oudst'. Dat komt echter niet uit de analyse naar voren. De gemiddelde academische leeftijd per cluster varieert tussen de 15,3 en 15,7 jaar. De verschillen in gemiddelde academische leeftijd tussen de clusters zijn dan ook verwaarloosbaar klein en niet statistisch significant. Wel is de spreiding in academische leeftijd voor het tweede cluster (het internationale cluster) het grootst met een groter aandeel jongere wetenschappers dan oudere wetenschappers. De mediane leeftijd is in dit cluster 14 jaar, terwijl die voor de andere twee clusters 16 jaar bedraagt.

Naast academische leeftijd hebben we informatie over het geslacht van de wetenschappers. Terwijl het aandeel vrouwen in de totale dataset ongeveer $25 \%$ bedraagt, zijn zij met 17,6\% ondervertegenwoordigd in cluster 1 (het professionele profiel) en met $29 \%$ oververtegenwoordigd in cluster 2 en 3 . Deze verschillen zijn echter niet statistisch significant.

Ten slotte hebben we informatie verzameld over de locatie van de promotie, zodat we kunnen nagaan of een promotie in het buitenland van invloed is op het publicatieprofiel. Bijna een vijfde van de wetenschappers in de dataset is aan een buitenlandse universiteit gepromoveerd. Zoals viel te verwachten is het aandeel 
Tabel 2 Multinomiale regressieanalyse met publicatieprofiel als afhankelijke variabele (internationaal $=$ referentiecategorie), B-coëfficiënten $(N=167)$

\begin{tabular}{|c|c|c|}
\hline & Cluster I & Cluster 3 \\
\hline Constante & $-0,972 *$ & $-2,683 * *$ \\
\hline Geslacht $(\operatorname{man}=1)$ & 0,630 & $-0,315$ \\
\hline $\begin{array}{l}\text { Academische leeftijd (aantal jaren } \\
\text { sinds promotie) }\end{array}$ & $-0,006$ & $-0,005$ \\
\hline $\begin{array}{l}\text { Locatie van promotie (Nederlandse } \\
\text { universiteit }=I \text { ) }\end{array}$ & $0,938^{* *}$ & $2,806 * * *$ \\
\hline Nagelkerke Pseudo R ${ }^{2}$ & 0,121 & \\
\hline -2 Log Likelihood & 216,622 & \\
\hline
\end{tabular}

personen dat aan een universiteit in het buitenland is gepromoveerd, het grootst in cluster $2(30,7 \%)$. Het aandeel personen dat in het buitenland is gepromoveerd, is het kleinst in cluster $3(2,7 \%)$. Cluster 1 zit daar tussenin: $15 \%$ van de wetenschappers in dit cluster is in het buitenland gepromoveerd, gezien het professionele en nationale publicatieprofiel een relatief hoog percentage. De verschillen zijn statistisch significant.

Om de invloed van deze kenmerken op de publicatiepatronen gelijktijdig en gecorrigeerd voor hun onderlinge samenhang te onderzoeken, hebben we als een laatste stap een multinomiale regressieanalyse uitgevoerd. De drie clusters zijn in deze analyse de afhankelijke variabele met cluster 2 (het internationale cluster) als de referentiecategorie. De drie achtergrondkenmerken, geslacht, academische leeftijd en locatie van promotie, zijn als onafhankelijke variabelen in de analyse opgenomen. De resultaten zijn samengevat in tabel 2. Voor een aantal cases kon de academische leeftijd of de locatie van promotie niet worden bepaald, ondanks een vraag per e-mail aan de betrokkenen.

Van de drie achtergrondkenmerken heeft uitsluitend de locatie van promotie een statistisch significant effect op het publicatieprofiel. Wetenschappers die aan een buitenlandse universiteit gepromoveerd zijn, hebben vergeleken met wetenschappers die aan een Nederlandse universiteit gepromoveerd zijn, vaker een internationaal publicatieprofiel dan een professioneel profiel $(B=0,938)$ of een traditioneel profiel $(B=2,806)$. Al met al geven de achtergrondkenmerken maar zeer beperkt een verklaring voor de publicatieprofielen. Deze bevinding suggereert dat de werkcontext eerder dan individuele achtergrondkenmerken doorslaggevend is voor het publicatieprofiel van bestuurs- en politieke wetenschappers. Onze gegevens laten inderdaad behoorlijke verschillen zien tussen de universiteiten. Zo is het professionele profiel dominant in Twente, Tilburg en Delft, het internationale profiel in Leiden en het traditionele profiel in Utrecht. De aantallen wetenschappers in onze dataset laten het helaas niet toe om na te gaan hoe de profielen per 
universiteit samenhangen met de achtergrondkenmerken van de wetenschappers en hun disciplinaire achtergrond. Het is daarbij ook nog de vraag in hoeverre afdelingen onderzoekers met een bepaald profiel aantrekken (selectie-effect) en in hoeverre tradities en de cultuur van afdelingen onderzoekers in de loop van de tijd beïnvloeden (socialisatie-effect).

\section{Conclusie}

In de bestuurs- en politieke wetenschappen wordt sinds lange tijd gediscussieerd over de verhouding tussen wetenschappelijke impact en de praktijkrelevantie van publicaties, de belangrijkste output van individuele wetenschappers. Deze discussies vinden plaats binnen bredere debatten over de ontwikkeling van de bestuurskunde en politieke wetenschappen als wetenschappelijke disciplines. Met de recente nadruk in het Nederlandse wetenschapsbeleid op maatschappelijke valorisatie heeft dit debat een nieuwe impuls gekregen. Met dit artikel hebben we een bijdrage aan deze discussie willen leveren door de publicaties van 177 bestuursen politieke wetenschappers in Nederland over de periode 2006-2011 te analyseren.

Drie publicatieprofielen komen uit de analyse naar voren: een professioneel profiel met een relatief hoog aandeel professionele publicaties, een internationaal profiel met een relatief hoog aandeel publicaties in internationale wetenschappelijke tijdschriften, en een traditioneel profiel met een bescheidener aantal publicaties gelijkelijk verdeeld over nationale en internationale professionele en wetenschappelijke publicaties. De onderscheiden profielen tonen dat er van een tradeoff tussen praktijkgericht en internationaal wetenschappelijk publiceren sprake is, maar dat enkel tot op zekere hoogte. Wetenschappers binnen de drie clusters hebben in de onderzochte periode immers verschillende typen publicaties op hun naam staan. Dit artikel geeft daarmee empirisch bewijs voor de aanname dat er twee stromingen in de publicatiecultuur bestaan, één gericht op nationale publicaties en banden met het werkveld, de andere op internationale publicaties, een aanname die nog niet eerder aan empirisch onderzoek onderworpen is geweest. Uit de resultaten blijkt echter ook dat de werkelijkheid genuanceerder is dan uit discussies over wetenschappelijk publiceren soms naar voren komt.

Terwijl onze analyse inzicht heeft geboden in de publicatieprofielen van bestuursen politieke wetenschappers in Nederland, zijn er ook kanttekeningen te plaatsen. Zo is de dataset niet representatief voor de politieke wetenschappers in Nederland, wat de bevindingen heeft kunnen vertekenen. Nemen we bijvoorbeeld de politieke wetenschappers aan de Universiteit van Amsterdam in beschouwing, dan zien we dat verschillende jonge wetenschappers nadrukkelijk de combinatie maken van internationaal wetenschappelijk publiceren en deelname aan het maatschappelijk debat onder meer door middel van praktijkgerichte en populaire publicaties. Een tweede kanttekening is dat we maar een beperkt aantal kenmerken van de wetenschappers en van hun werkcontext in de analyse konden opnemen. Voor meer inzicht in de drijfveren en opbrengsten van publiceren in de 
bestuurs- en politieke wetenschappen moeten we dit met elkaar blijven bespreken.

\section{Literatuur}

Bueren, E. van. (2010). Bestuurskunde en bestuur: Een verstoorde relatie? Bestuurskunde, 19 (1), 82-85.

Bushouse, B.K., Jacobson, W.S., Lambright, K.T., Llorens, J.J., Morse, R.S., \& Poocharoen, O.-O. (2011). Crossing the divide: Building bridges between public administration practitioners and scholars. Journal of Public Administration Theory and Practice, 21, i99i112.

Eisfeld, R. (2011). How political science might regain relevance and obtain an audience: A manifesto for the 21st century. European Political Science, 10(2), 220-225.

Flinders, M., \& John, P. (2013). The future of political science. Political Studies Review, 11(2), 222-227.

Frissen, P., \& Twist, M. van. (2010). Bestuurskundige advisering als avontuur. In H. Aardema, W. Derksen, M. Herweijer \& P. de Jong (red.), Meerwaarde van de bestuurskunde: Liber Amicorum voor prof. dr. Arno F.A. Korsten (pp. 37-48). Den Haag: Boom Lemma uitgevers.

Gibson, P.A., \& Deadrick, D. (2010). Public administration research and practice: Are academician and practitioner interests different? Public Administration Quarterly, 34(2), 145-168.

Kaufman, L., \& Rousseeuw, P.J. (2009). Finding groups in data: An introduction to cluster analysis (Vol. 344). Hoboken NJ: John Wiley and Sons.

Kellough, J.E., \& Pitts, D.W. (2005). Who contributes to Public Administration Review? Examining the characteristics of authors who submit manuscripts to the journal. Public Administration Review, 65(1), 3-7.

Kieser, A., \& Leiner, L. (2009). Why the rigour-relevance gap in management research is unabridgeable. Journal of Management Studies, 46(3), 516-533.

Kieser, A. \& Leiner, L. (2012). Collaborate with practitioners: But beware of collaborative research. Journal of Management Inquiry, 21(1), 14-28.

Mole, B. (2013, August 2). NSF cancels political-science grant cycle. Nature news.

Norusis, M. (2011). IBM SPSS Statistics 19 Statistical Procedures Companion. Upper Saddle River, NJ: Prentice Hall.

NWO Maatschappij- en Gedragswetenschappen. (2013). Onderzoek publicatieculturen NWO-MaGW. Den Haag: NWO.

Putnam, R. (2003). The public role of political science. Perspectives on Politics, 1(2), 249-255.

Rencher, A.C., \& Christensen, W.F. (2002). Methods of multivariate analysis (Vol. 709). Hoboken, NJ: John Wiley \& Sons.

Renwick Monroe, K. (2005). Perestroika! The raucous rebellion in political science. New Haven: Yale University Press.

Schroeder, L., O’Leary, R., Jones, D., \& Poocharoen, O.-O. (2004). Routes to scholarly success in public administration: Is there a right path? Public Administration Review, 64(1): 92-105.

Stoker, G. (2010). Blockages on the road to relevance: Why has political science failed to deliver? European Political Science, 9(1), 72-84.

Streib, G., Slotkin, B.J., \& Rivera, M. (2001). Public administration research from a practitioner perspective. Public Administration Review, 61(5), 515-525. 
Trent, J.E. (2011). Should political science be more relevant? An empirical and critical analysis of the discipline. European Political Science, 10(2), 191-209.

Waldo, D. (1955). The study of public administration. New York: Doubleday. 